\title{
Crystal structure of terbium antimonide oxide, $\mathrm{Tb}_{9} \mathrm{Sb}_{5} \mathrm{O}_{5}$
}

\author{
Jürgen Nuss and Martin Jansen* \\ Max-Planck-Institut für Festkörperforschung, Heisenbergstraße 1, 70569 Stuttgart, Germany
}

Received December 19, 2008, accepted and available on-line January 16, 2009; CSD no. 409978

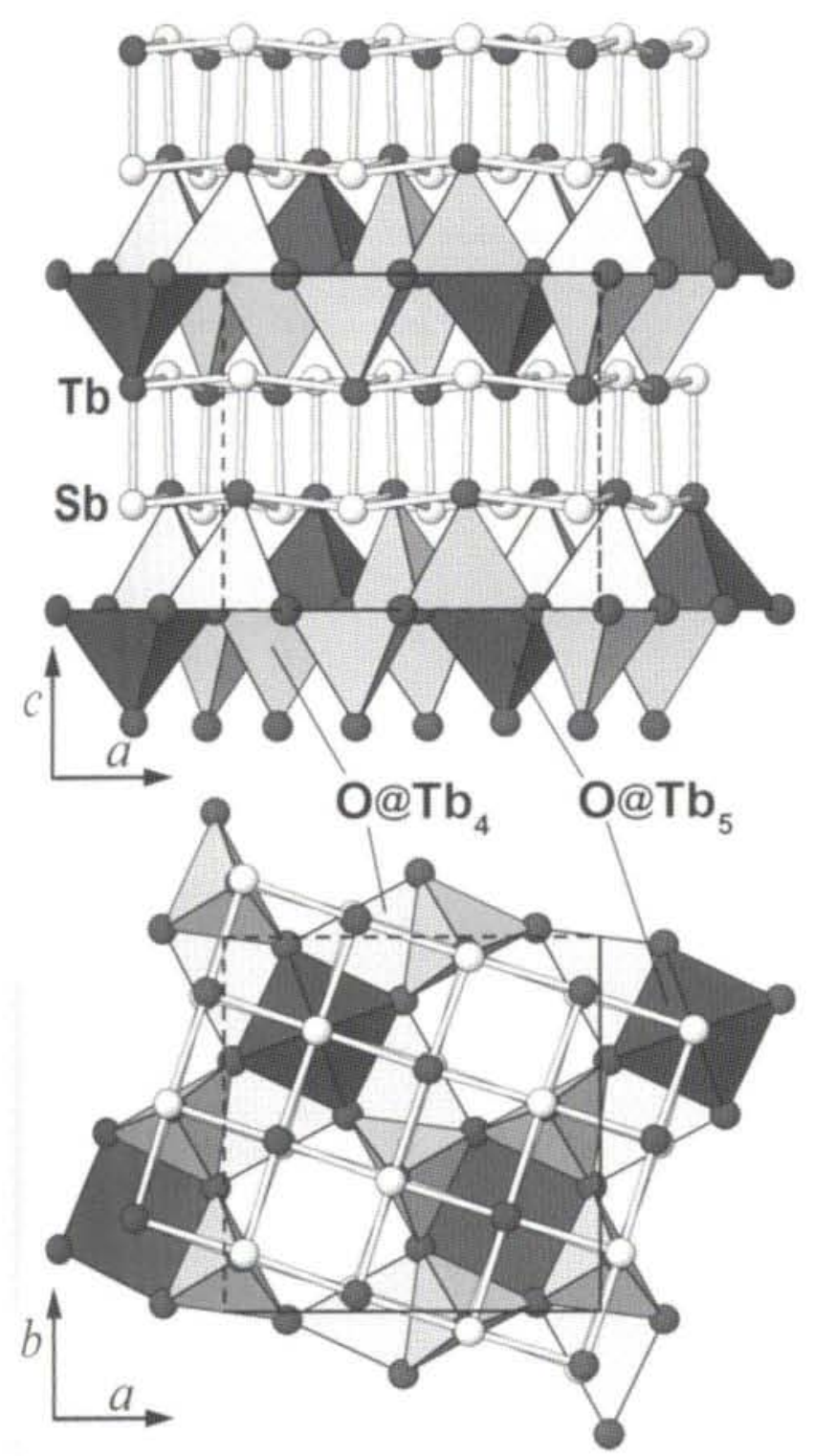

ture profile was applied: $298 \rightarrow 1923 \mathrm{~K}\left(50 \mathrm{Kh}^{-1}\right.$, subsequent annealing for $12 \mathrm{~h}) ; 1923 \rightarrow 1673 \mathrm{~K}\left(20 \mathrm{Kh}^{-1}\right.$, subsequent annealing for $48 \mathrm{~h}) ; 1673 \rightarrow 298 \mathrm{~K}\left(20 \mathrm{Kh}^{-1}\right)$.

\section{Discussion}

$\mathrm{Tb}_{9} \mathrm{Sb}_{5} \mathrm{O}_{5}$ crystallize in the $\mathrm{LagS}_{5} \mathrm{O}_{5}$ type of structure $[1,2]$. The atoms $\mathrm{Tb} 2, \mathrm{~Tb} 3$ and $\mathrm{Sb} 1, \mathrm{Sb} 2$ are aranged in a corrugated double layer [TbSb], which can be regarded as a two-dimensional slab analogous to $\mathrm{NaCl}$. Each [TbSb] fragment is sandwiched between two layers built from $\mathrm{Tb} 1$ and $\mathrm{O} 1, \mathrm{O} 2$. The $\mathrm{NaCl}$-like double sheet is also a feature common to the structures of $\mathrm{Eu}_{4} \mathrm{Sb}_{2} \mathrm{O}$ [3] or $\mathrm{Sc}_{2} \mathrm{Sb}$ [4]. In the latter compound the interlayer exclusively consists of $\mathrm{Sc}$ atoms. In the case of $\mathrm{Tb}_{9} \mathrm{Sb}_{5} \mathrm{O}_{5}$ this layer is composed of $\mathrm{Tb}$ and $\mathrm{O}$ atoms with the composition $\mathrm{Tb}_{4} \mathrm{O}_{5}$, and only $4 / 5$ of the possible metal positions are occupied by terbium. Therefore, the structure can be regarded as a defect variant of $\mathrm{Sc}_{2} \mathrm{Sb}$, stuffed with oxygen: $\mathrm{Tb}_{9} \square \mathrm{Sb}_{5} \mathrm{O}_{5}=\mathrm{Sc}_{10} \mathrm{Sb}_{5} \square_{5}$. From the originally square $S c_{5}$ pyramids, with their tips alternating up and down along the [001] direction, 4/5 transform into tetrahedra and 1/5 remain unchanged. All tetrahedral and square-pyramidal holes are filled with $\mathrm{O}$ atoms. The partial structure ( $\left.\mathrm{Tb}_{9} \mathrm{Sb}_{5}\right)$ also corresponds to the inverted $\mathrm{Hf}_{5} \mathrm{Sb}$ g type of structure [5]. The buckling of the $\mathrm{NaCl}$-like slabs is one way to fit the dimensions of their meshes to the sandwiched sheets inbetween [6]. Here in $\mathrm{Tb}_{9} \mathrm{Sb}_{5} \mathrm{O}_{5}$, the present of vacancies in the $\mathrm{Tb}_{4} \mathrm{DO}_{5}$ sublattice, allows an additional adjustment, which is needed because of $d(\mathrm{~Tb}-\mathrm{Sb})=3.143 \AA<2^{1 / 2} d(\mathrm{~Tb}-\mathrm{O})=3.325 \AA$.

Table 1. Data collection and handling.

$\begin{array}{ll}\text { Crystal: } & \begin{array}{l}\text { dark silver block, } \\ \text { size } 0.01 \times 0.02 \times 0.02 \mathrm{~mm}\end{array} \\ \text { Wo } K_{\alpha} \text { radiation }(0.71073 \AA) & 441.78 \mathrm{~cm}^{-1} \\ \mu: & \text { SMART APEX II, Bruker AXS, } \omega \\ \text { Diffractometer, scan mode: } & 74.4^{\circ} \\ 2 \theta_{\text {max }} & 16398,2211 \\ N(h k l)_{\text {measured }}, N(h k l)_{\text {unique }}: & I_{\text {obs }}>2 \sigma\left(I_{\text {obs }}\right), 1615 \\ \text { Criterion for } I_{\text {obs, }} N(h k l)_{\text {gt }}: & 47 \\ N(\text { param })_{\text {refined: }} & \text { SHELXS-97 [7], SHELXL-97 [8], } \\ \text { Programs: } & \text { ATOMS [9] }\end{array}$

\begin{abstract}
$\mathrm{O}_{5} \mathrm{Sb}_{5} \mathrm{~Tb}$, tetragonal, $P 4 / n$ (no. 85), $a=9.862(1) \AA$, $c=8.838(2) \AA, V=859.5 \AA^{3}, Z=2, R_{g t}(F)=0.030$, $w R_{\text {ref }}\left(F^{2}\right)=0.049, T=296 \mathrm{~K}$.
\end{abstract}

\section{Source of material}

$\mathrm{Tb}_{9} \mathrm{Sb}_{5} \mathrm{O}_{5}$ has been synthesized from terbium metal, antimony, and $\mathrm{Sb}_{2} \mathrm{O}_{3}$. Stoichiometric amounts of the starting materials were mixed and sealed in a tantalum ampoule. The following tempera-

\footnotetext{
* Correspondence author (e-mail: M.Jansen@fkf.mpg.de)
} 
Table 2. Atomic coordinates and displacement parameters (in $\AA^{2}$ ).

\begin{tabular}{lllllllllll}
\hline Atom & Site & $x$ & $y$ & 2 & $U_{11}$ & $U_{22}$ & $U_{33}$ & $U_{12}$ & $U_{13}$ & $U_{23}$ \\
\hline $\mathrm{Tb}(1)$ & $8 g$ & $0.33120(2)$ & $0.02250(2)$ & $0.99800(3)$ & $0.0049(1)$ & $0.0073(1)$ & $0.00766(9)$ & $0.00007(8)$ & $-0.00054(9)$ & $0.00030(9)$ \\
$\mathrm{Tb}(2)$ & $2 c$ & $1 / 4$ & $1 / 4$ & $0.33136(6)$ & $0.0093(1)$ & $U_{11}$ & $0.0057(2)$ & 0 & 0 & 0 \\
$\mathrm{~Tb}(3)$ & $8 g$ & $0.14585(3)$ & $-0.04496(3)$ & $0.65470(3)$ & $0.0090(1)$ & $0.0090(1)$ & $0.0055(1)$ & $-0.00048(9)$ & $0.00012(9)$ & $-0.00048(9)$ \\
$\mathrm{Sb}(1)$ & $2 c$ & $1 / 4$ & $1 / 4$ & $0.68537(9)$ & $0.0071(2)$ & $U_{11}$ & $0.0109(3)$ & 0 & 0 & 0 \\
$\mathrm{Sb}(2)$ & $8 g$ & $0.15426(4)$ & $-0.05428(3)$ & $0.30038(4)$ & $0.0071(2)$ & $0.0079(2)$ & $0.0067(1)$ & $-0.0003(1)$ & $0.0004(1)$ & $0.0001(1)$ \\
$\mathrm{O}(1)$ & $2 c$ & $1 / 4$ & $1 / 4$ & $0.067(1)$ & $0.012(2)$ & $U_{11}$ & $0.023(5)$ & 0 & 0 \\
$O(2)$ & $8 g$ & $0.1284(4)$ & $-0.0239(4)$ & $0.9117(4)$ & $0.009(2)$ & $0.007(2)$ & $0.008(2)$ & $-0.001(1)$ & $0.000(1)$ & $-0.000(1)$ \\
& & & & & & & & & &
\end{tabular}

Acknowledgment. The authors gratefully acknowledge the help of Mrs. S. Prill-Diemer for carrying out the synthesis.

\section{References}

1. Nuss, J.; von Schnering, H. G.; Grin, Yu.: On the Antimonide Oxides $\mathrm{LagSb}_{5} \mathrm{O}_{5}$ and $\mathrm{Ce}_{9} \mathrm{Sb}_{5} \mathrm{O}_{5}$ as well as the binary phases $\mathrm{La}_{2} \mathrm{Sb}$ and $\mathrm{Ce}_{2} \mathrm{Sb} . \mathrm{Z}$. Anorg. Allg. Chem. 630 (2004) 2287-2291.

2. Nuss, J.; Jansen, M.: Reticular merohedral twinning within the $\mathrm{LagSb}_{5} \mathrm{O}_{5}$ structure family: structure of $\mathrm{Pr}_{9} \mathrm{Sb}_{5} \mathrm{O}_{5}, \mathrm{Sm}_{9} \mathrm{Sb}_{5} \mathrm{O}_{5}$ and $\mathrm{Dy}_{9} \mathrm{Sb}_{5} \mathrm{O}_{5}$. Acta Crystallogr. B63 (2007) 843-849.

3. Schaal, H.; Nuss, J.; Hönle, W.; Grin, Yu.; von Schnering, H. G.: Crystal structure of tetraeuropium diantimonide oxide, $\mathrm{Eu}_{4} \mathrm{Sb}_{2} \mathrm{O}$. Z. Kristallogr. NCS 213 (1998) 15.

4. Nuss, J.; Jansen, M.: Crystal structure of discandium antimonide, $\mathrm{Sc}_{2} \mathrm{Sb}$. Z. Kristallogr. NCS 217 (2002) 19-20.

5. Assoud, A.; Kleinke, K. M.; Soheilnia, N.; Kleinke, H.: T-Shaped Nets of Antimony Aloms in the Binary Antimonide $\mathrm{Hf}_{5} \mathrm{Sb}_{9}$. Angew. Chem. Int. Ed. 43 (2004) 5260-5262.

6. Nuss, J.; Wedig, U.; Jansen, M.: Geometric variations and electron localizations in intermetallics: $\mathrm{PbFCl}$ type compounds: $\mathrm{Z}$. Kristallogr. 221 (2006) 554-562.

7. Sheldrick, G. M.: SHELLXS-97. Program for the Solution of Crystal Structures. University of Götingen, Germany 1997.

8. Sheldrick, G. M.: SHELXI-97. Program for the Refinement of Crystal Structures. University of Göttingen, Germany 1997.

9. Dowty, E.: ATOMS. A Complete Program for Displaying Atomic Structures. Version 6.3. Shape Software, Kingsport, Tennessee, USA 2006. 